\title{
Loss Minimization of Power Distribution Network using Different Types of Distributed Generation Unit
}

\author{
Su Hlaing Win*, Pyone Lai Swe ** \\ * Department of Electrical Power Engineering, Mandalay Technological University, Myanmar \\ ** The Republish of the Union of Myanmar, Myanmar
}

\begin{tabular}{l} 
Article Info \\
\hline Article history: \\
Received May 9, 2015 \\
Revised Jul 10, 2015 \\
Accepted Jul 21, 2015 \\
\hline
\end{tabular}

Keyword:

Distributed generation

Exact loss formula

Four types of DG

Optimal location and sizing

Power loss minimization

\begin{abstract}
A Radial Distribution network is important in power system area because of its simple design and reduced cost. Reduction of system losses and improvement of voltage profile is one of the key aspects in power system operation. Distributed generators are beneficial in reducing losses effectively in distribution systems as compared to other methods of loss reduction. Sizing and location of DG sources places an important role in reducing losses in distribution network. Four types of DG are considered in this paper with one DG installed for minimize the total real and reactive power losses. The objective of this methodology is to calculate size and to identify the corresponding optimum location for DG placement for minimizing the total real and reactive power losses and to improve voltage profile in primary distribution system. It can obtain maximum loss reduction for each of four types of optimally placed DGs. Optimal sizing of Distributed Generation can be calculated using exact loss formula and an efficient approach is used to determine the optimum location for Distributed Generation Placement. To demonstrate the performance of the proposed approach 36-bus radial distribution system in Belin Substation in Myanmar was tested and validated with different sizes and the result was discussed.
\end{abstract}

Copyright (C) 2015 Institute of Advanced Engineering and Science. All rights reserved.

\section{Corresponding Author:}

Su Hlaing Win,

Department of Electrical Power Engineering, Mandalay Technological University

Email: suhlaingwin24@gmail.com

\section{INTRODUCTION}

In recent years, environmental concerns, fuel cost uncertainties, liberalization of electricity markets and advances in technology have resulted in increasing DG units in distribution system. This trend has offered great opportunities but created several challenges in planning and operations of distribution systems. The primary purpose of DG units is energy injection; however, strategically placed and operated DG units can yield several other benefits to utilities. A typical example of such benefit is the application of DG units for loss reduction [1-3]. Voltage and load ability enhancement, reliability improvement and network upgrade deferral are other benefits $[4,5]$.

Distributed Generation is an emerging technology in this new era and it provides clean electric power. Distributed Generation should be located at or near an electrical load Centre. Installation of Distributed Generation at optimal places provides the clean electric power to the customer [6]. Different issues have been mentioned to define the Distributed generation more importantly. Some of the issues of DG is Distributed Generation Rating, then other are Technology, sizing, sitting, mode of operation, Distributed Generation penetration [7].Distributed Generation is a small generating unit located in the effective point of the electric power system near to the load centre.

DG systems are small power sources that connect to distribution systems. With the increasing demand for electrical power and the technical, economic, and environmental constraints in the construction 
of new power plants and new transmission lines, DG can efficiently respond to system requirements. DG has predominant specifications.

There are a number of DG technologies available in the market today and few are still in research and development stage. Some currently available technologies are reciprocat ing engines, micro turbines, combustion gas turbines, fuel cells, photovoltaic, and wind turbines. Each one of these technologies has its own benefits and characteristics. Among all the DG, diesel or gas reciprocating engines and gas turbines make up most of the capacity installed so far. Simultaneously, new DG technology like micro turbine is being introduced and an older technology like reciprocating engine is being improved [8]. Fuel cells are technology of the future. However, there are some proto-type demonstration projects.

In this paper exact loss formula method is used to calculate optimal DG unit's size and proper location. So that the real power losses, reactive power losses were minimized and the corresponding voltage profile values were improved. The proposed approach has been tested on 36-bus distribution system in Belin Substation in Myanmar. Result obtain from this approach clearly explains the optimal location and sizing of DG there by minimizes the power losses of the system. The remainder of this paper is structured as follows Section II presents Problem Formulation, Section III explains about Proposed Methodology, Section IV describes about Simulation Results and Discussions, and finally Section V explains about Conclusion.

\section{PROBLEM FORMULATION}

The objective of problem is to find the location of DGs and its size for type-1, type-2, type- 3 and type-4 DG to minimize the real and reactive power losses and to improve the voltage profile. Real Power loss in the system can be calculated by equation (1), given the system operating condition,

$$
P_{L}=\sum_{i=1}^{N} \sum_{j=1}^{N}\left[\alpha_{i j}\left(P_{i} P_{j}+Q_{i} Q_{j}\right)+\beta_{i j}\left(Q_{i} P_{j}-P_{i} Q_{j}\right)\right]
$$

Where,

$$
\begin{aligned}
& \alpha_{i j}=\frac{r_{i j}}{\left|V_{i}\right|\left|V_{j}\right|} \cos \left(\delta_{i}-\delta_{j}\right) \\
& \beta_{i j}=\frac{r_{i j}}{\left|V_{i}\right|\left|V_{j}\right|} \sin \left(\delta_{i}-\delta_{j}\right)
\end{aligned}
$$

The minimize reactive power loss will have significant impact on voltage stability of the power system. The reactive power loss formula is given by equation (4),

$$
\mathrm{Q}_{\mathrm{L}}=\sum_{j=1}^{N} \sum_{k=1}^{N}\left[V_{j k}\left(\mathrm{P}_{\mathrm{j}} \mathrm{P}_{\mathrm{k}}+\mathrm{Q}_{\mathrm{j}} \mathrm{Q}_{\mathrm{k}}\right)+\zeta_{j k}\left(\mathrm{Q}_{\mathrm{j}} \mathrm{P}_{\mathrm{k}}-\mathrm{P}_{\mathrm{j}} \mathrm{Q}_{\mathrm{k}}\right)\right]
$$

Where,

$$
\begin{aligned}
& \gamma_{j k}=\frac{X_{j k}}{V_{j} V_{k}} \cos \left(\delta_{j}-\delta_{k}\right) \\
& \zeta_{j k}=\frac{\mathrm{X}_{\mathrm{jk}}}{\mathrm{V}_{\mathrm{j}} \mathrm{V}_{\mathrm{k}}} \sin \left(\delta_{\mathrm{j}}-\delta_{\mathrm{k}}\right)
\end{aligned}
$$

$P_{i}$ is real power flow at bus $i$ in $\mathrm{MW}$

$Q_{i}$ is reactive power flow at bus $i$ in MVAR

$P_{j}$ is real power flow at bus $\mathrm{j}$ in MW

$Q_{j}$ is reactive power flow at bus $j$ in MVAR 
$R_{i j}$ is resistance of the line connecting bus $i$ and $j$ in Ohms

$\mathrm{X}_{\mathrm{ij}}$ is Reactance of the line connecting bus $\mathrm{i}$ and $\mathrm{j}$ in Ohms

$\mathrm{V}_{\mathrm{i}}$ and $\mathrm{V}_{\mathrm{j}}$ are bus voltage magnitude at bus $\mathrm{i}$ and $\mathrm{j}$ in PU

$\delta_{\mathrm{i}}$ and $\delta_{\mathrm{j}}$ are bus voltage angle at bus $\mathrm{i}$ and $\mathrm{j}$

\subsection{Type-1 DG}

Photo voltaic, micro turbines, fuel cells which are integrated to main grid with the help of converters/inverters are good examples of type1.

For type-1 DG, the optimal size of DG at each bus i for minimizing losses is given by equation (7).

$$
\begin{aligned}
& P_{D G i}=P_{D i}+\frac{1}{\alpha_{i i}}\left[\beta_{i i} Q_{i}+\sum_{j=1, j \neq i}^{N}\left(\alpha_{i j} P_{j}-\beta_{i j} Q_{j}\right)\right] \\
& P_{i}=P_{D G i}-P_{D i}
\end{aligned}
$$

Real power loss reduction by $\mathrm{DG}$,

$$
\mathrm{PLR}=\frac{\mathrm{P}_{\text {Loss }}-\mathrm{P}_{\text {Loss }}^{\mathrm{DG}}}{\mathrm{P}_{\text {Loss }}} \times 100 \%
$$

\subsection{Type-2 DG}

Synchronous motors such as gas turbines are examples for type2.

For type-2 DG, the optimal size of DG at each bus i for minimizing losses is given by equation (9),

$$
\begin{aligned}
& \mathrm{Q}_{\mathrm{DGi}}=\mathrm{Q}_{\mathrm{Di}}+\frac{1}{\alpha_{\mathrm{ii}}}\left[\beta_{\mathrm{ii}} \mathrm{P}_{\mathrm{i}}-\sum_{j=1, j \neq i}^{N}\left(\alpha_{i j} Q_{j}+\beta_{i j} P_{j}\right)\right] \\
& \mathrm{Q}_{\mathrm{i}}=\mathrm{Q}_{\mathrm{DGi}}-\mathrm{Q}_{\mathrm{Di}}
\end{aligned}
$$

Reactive power loss reduction by DG,

$$
\mathrm{QLR}=\frac{\mathrm{Q}_{\text {Loss }}-\mathrm{Q}_{\text {Loss }}^{\mathrm{DG}}}{\mathrm{Q}_{\text {Loss }}} \times 100 \%
$$

\subsection{Type-3 DG}

DG units that are based on synchronous machine fall in type 3 . The combination of both $\mathrm{P}_{\mathrm{DGi}}$ and $Q_{\text {DGi }}$ injected at the same bus i can produce the optimal size of Type 3 DG,

$$
S_{D G i}=\sqrt{P_{D G i}^{2}+Q_{D G i}^{2}}
$$

\subsection{Type-4 DG}

The DG will supply real power and in turn will absorb reactive power. In case of the wind turbines, induction generator is used to produce real power and the reactive power will be consumed in the process.

$$
Q_{D G}=-\left(0.5+0.04 P_{D G}^{2}\right)
$$

The optimal sizes at various locations have been calculated for different types of DG and the losses are calculated with optimal sizes for each case. The case with minimum losses is selected as optimal location for each type DG. 


\section{PROPOSED METHODOLOGY}

A computer program has been written in MATLAB to calculate the optimal sizes of DG at various bus and approximate total losses with DG at different locations identify the best location. A Newton-Raphson algorithm based load flow program is used to solve the load flow problem.

The 36-bus distribution system is extracted from $230 / 33 / 11 \mathrm{kV}$ Belin Substation in Kyaukse area of Myanmar. This radial distribution system consists of six main feeder. The total real and reactive power loads are 200MW and 198 MVAr, respectively. The Belin distribution system, is as shown in Figure 1.

Incoming line of Belin station is $230 \mathrm{kV}$ line. There are thirty five outgoing lines. Their rated voltage is $33 \mathrm{kV}$ line. Analytical method is applied for optimal size and location of distributed generation.

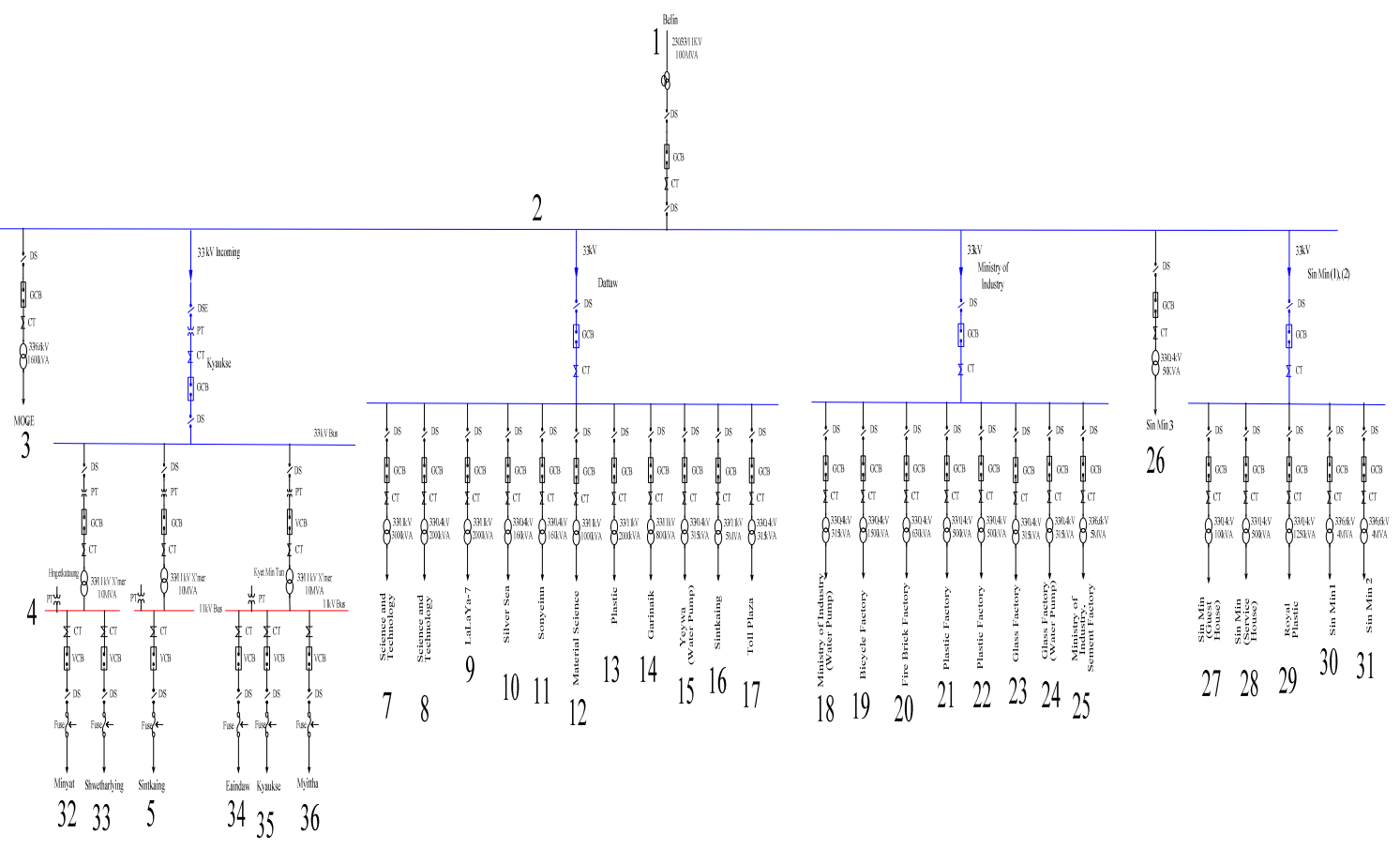

Figure 1. Single line diagram of Belin Substation in Myanmar

\section{SIMULATION RESULTS AND DISCUSSIONS}

The Proposed Methodology is tested on 36-bus distribution system in Belin Substation in Myanmar with different sizes are simulated in MATLAB environment to calculate the optimum DG sizes for various buses and approximate total power loss with DG at various location. The line parameters and load data are listed in Appendix. The data are based on 100 MVA.

\subsection{Optimum Size Allocation}

Based on the proposed approach optimum sizes of DG's are determined using equation (7) and (10) at various nodes for Belin distribution system in Myanmar. In Belin distribution system optimum sizes of DG ranging from 4.6 MW to 97.2 MW and 1.67 MVAR to 72.2 MVAR. After connecting DG's one by one it is important to note that the total power loss is lowest at the corresponding buses. 


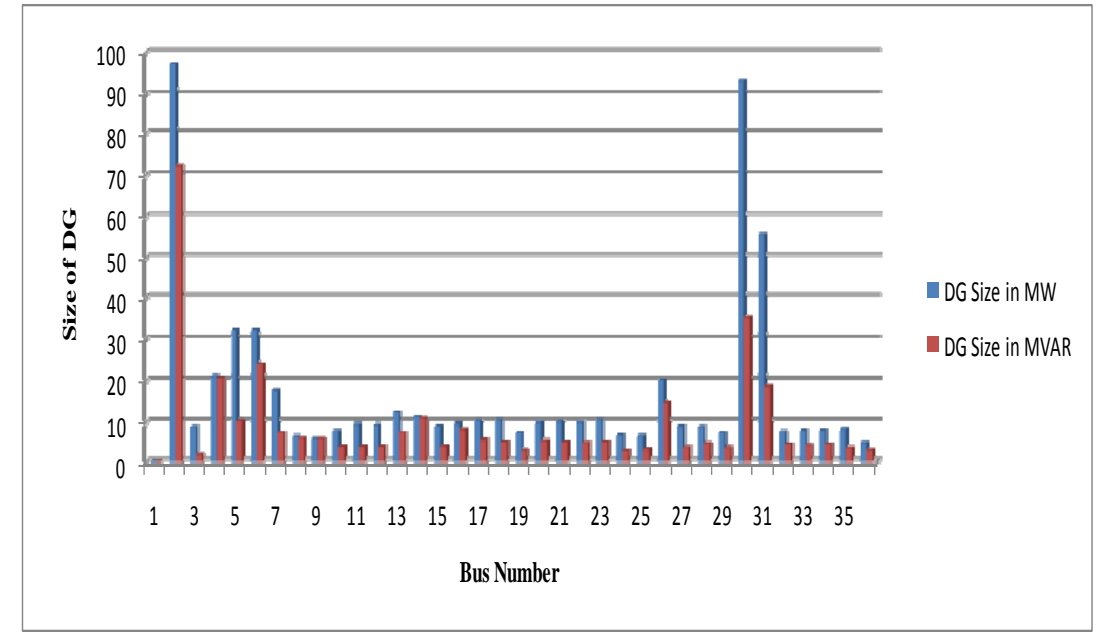

Figure 2. Optimum real and reactive power sizes of type 1 and type 2 DG at 36 bus distribution system at Belin Substation in Myanmar

Based on this result of DG sizing the optimal location of DG is determined where the total real and reactive power loss is minimum at the respective buses. Figure 2 shows the optimum real and reactive power sizes of type 1 and type 2 DG at 36- bus Belin distribution system. Figure 3 shows the optimum size of type 3 DG at various nodes for 36 bus distribution system. As far as one location is concerned, in a distribution system, Figure 3 would give the value of DG size to have a possible minimum total loss. The range of optimum sizes of type $3 \mathrm{DG}$ is from $0.3 \mathrm{MW}$ to $3.9 \mathrm{MW}$. Now, it is important to identify the location in which the total power loss will be minimal.

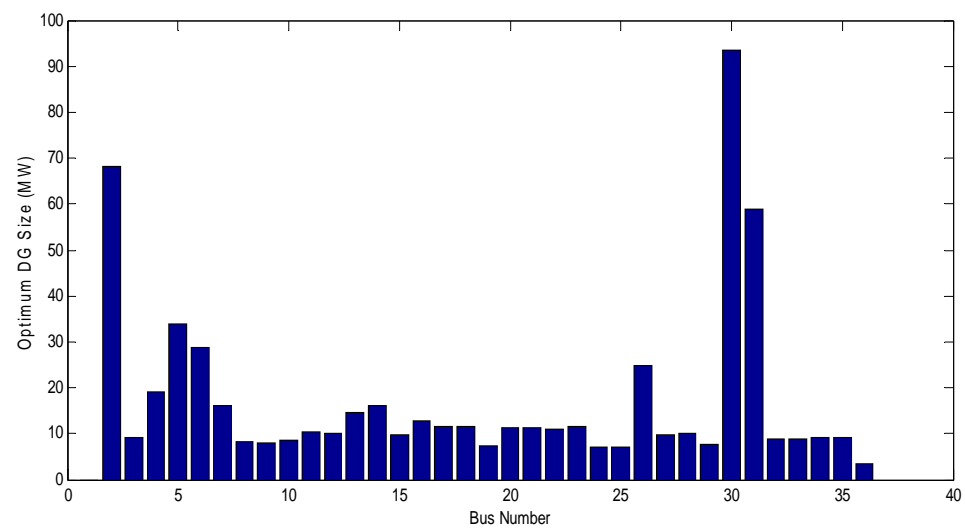

Figure 3. Optimum size of type $3 \mathrm{DG}$ at 36 bus distribution system at Belin Substation in Myanmar

Figure 4 shows the bar representation of optimal sizes of type 4 DG at all buses for 36 bus system. From figure, it can be observed that the DG size do not follow a regular manner and the size is independent of location of bus. 


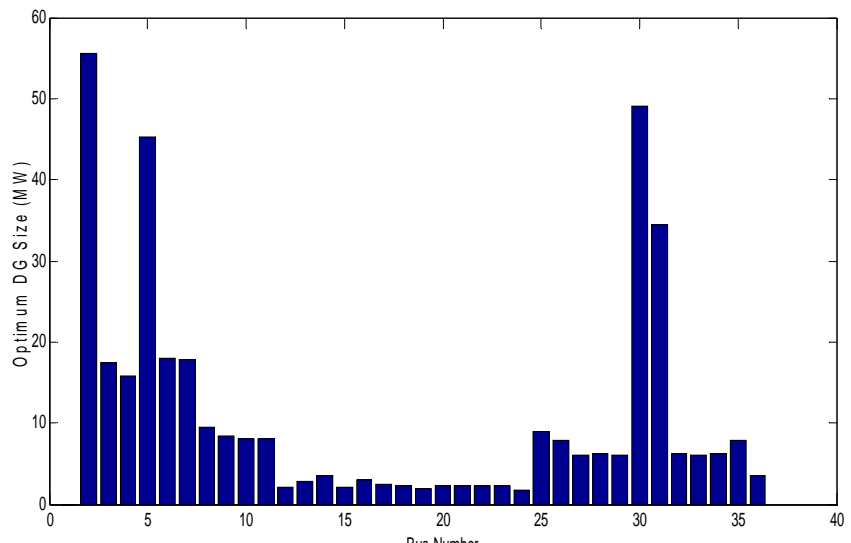

Figure 4. Optimum size of type 4 DG at 36 bus distribution system in Belin Substation

\subsection{Selection of Optimum Location}

With the help of optimum DG sizes obtained at various nodes it is best enough to find out the optimum location that would leads to calculate the least total power losses. In Belin distribution system bus 24 is located as optimal placement of DG. After DG placement total real and reactive power losses are reduced and average real power loss is reduced from $0.2767 \mathrm{MW}$ to $0.2030 \mathrm{MW}$ and average reactive power loss is reduced to the range of 0.4763 MVAR to 0.0491 MVAR. Table 1 shows the result of average real and reactive power loss after connecting DG at Belin distribution system in Myanmar.

Table 1. Result of average real and reactive power loss after connecting DG at Belin distribution system

\begin{tabular}{|c|c|c|c|c|}
\hline $\begin{array}{l}\text { Bus Number at which } \\
\text { DG Connected }\end{array}$ & $\begin{array}{l}\text { Size of DG in } \\
\text { MW }\end{array}$ & $\begin{array}{l}\text { Size of DG in } \\
\text { MVAR }\end{array}$ & $\begin{array}{l}\text { Average Real Power Loss } \\
\text { in MW }\end{array}$ & $\begin{array}{l}\text { Average Reactive Power Loss } \\
\text { in MVAR }\end{array}$ \\
\hline 1 & 0 & 0 & 2.095 & 0.3301 \\
\hline 2 & 97.2 & 72.2 & 2.929 & 1.371 \\
\hline 3 & 8.94 & 1.67 & 0.3405 & 0.0253 \\
\hline 4 & 21.1 & 20.7 & 0.2635 & -0.6205 \\
\hline 5 & 32.3 & 10.3 & 0.5433 & 0.1644 \\
\hline 6 & 32.3 & 24.1 & 0.195 & -0.6637 \\
\hline 7 & 17.6 & 7.17 & 0.2107 & 0.1118 \\
\hline 8 & 6.09 & 5.64 & 0.2184 & 0.0494 \\
\hline 9 & 5.59 & 5.57 & 0.2202 & 0.0329 \\
\hline 10 & 7.83 & 3.58 & 0.2949 & 0.0562 \\
\hline 11 & 9.6 & 3.68 & 0.2980 & 0.06334 \\
\hline 12 & 9.42 & 3.6 & 0.2930 & 0.06803 \\
\hline 13 & 12.5 & 7.35 & 0.4003 & 0.0167 \\
\hline 14 & 11.4 & 11.1 & 0.2673 & -0.0836 \\
\hline 15 & 9.09 & 3.81 & 0.2954 & 0.03969 \\
\hline 16 & 9.62 & 8.36 & 0.2070 & -0.1005 \\
\hline 17 & 10.4 & 5.2 & 0.3167 & 0.045 \\
\hline 18 & 10.5 & 4.71 & 0.2180 & 0.1062 \\
\hline 19 & 6.96 & 2.84 & 0.3188 & 0.06915 \\
\hline 20 & 10 & 4.95 & 0.316 & 0.01913 \\
\hline 21 & 10.1 & 4.74 & 0.3134 & 0.02826 \\
\hline 22 & 10 & 4.62 & 0.3178 & 0.1055 \\
\hline 23 & 10.5 & 4.8 & 0.01098 & 0.09646 \\
\hline 24 & 6.43 & 2.7 & 0.2030 & 0.0491 \\
\hline 25 & 6.29 & 3 & 0.4881 & 0.09892 \\
\hline 26 & 20.1 & 14.8 & 0.2801 & 0.1374 \\
\hline 27 & 9.06 & 3.5 & 0.3204 & 0.0774 \\
\hline 28 & 9.05 & 4.46 & 0.2014 & 0.0722 \\
\hline 29 & 6.99 & 3.47 & 0.2337 & 0.0347 \\
\hline 30 & 93.2 & 35.3 & 4.004 & -2.19 \\
\hline 31 & 55.8 & 18.7 & 2.202 & 0.1365 \\
\hline 32 & 7.8 & 4.18 & 0.1782 & 0.03534 \\
\hline 33 & 8 & 4.01 & 0.1759 & 0.05015 \\
\hline 34 & 8.1 & 4.36 & 0.2028 & 0.05739 \\
\hline 35 & 8.5 & 3.31 & 0.2284 & 0.06512 \\
\hline 36 & 4.6 & 2.75 & 0.1025 & -0.1268 \\
\hline
\end{tabular}


Figure 5 shows the real power losses of the system are reduced by optimal placement of type 3 DG, type 4 DG and without DG.

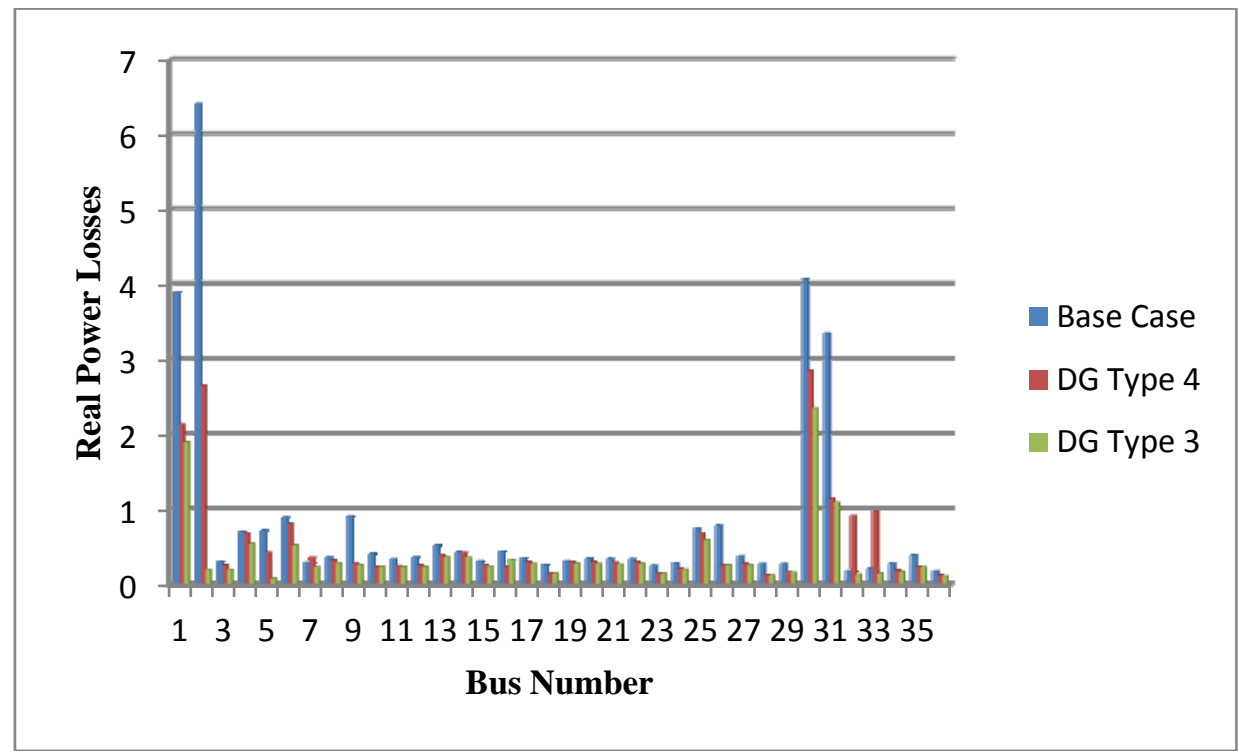

Figure 5. Real power losses at buses DG Type 4, DG Type 3 and without DG

Figure 6 shows the total reactive power losses of the system for different locations of DG with the size obtained from the previous section.

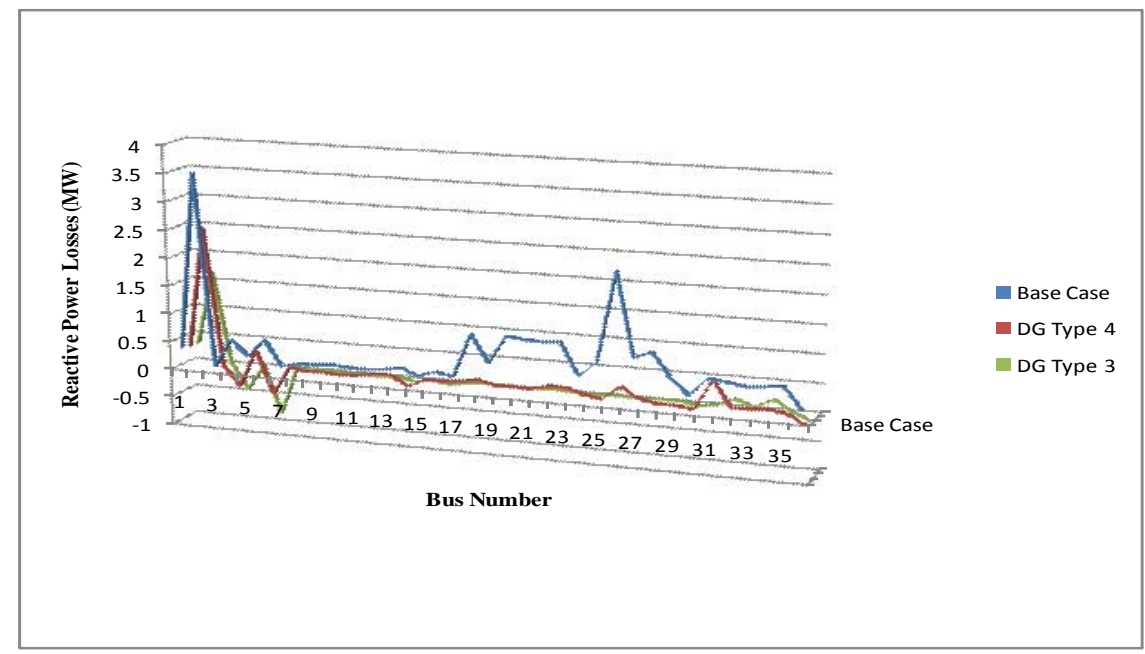

Figure 6. Reactive power losses at buses DG Type 4, DG Type 3 and without DG

Table 2 shows the optimal location and the optimal size of type-1 DG at 36 bus distribution system in Myanmar. 
Table 2. Optimal DG Type-1 Placement of the System

\begin{tabular}{ccccc}
\hline DG installed & DG Type 1 & DG Type 1 & DG Type 1 & DG Type 1 \\
\hline Location & 24 & 30 & 5 & 33 \\
PDG size, MW & 6.43 & 93.2 & 32.3 & 8 \\
Ploss, MW & 0.1098 & 0.2186 & 0.5433 & 0.1759 \\
Ploss reduction, $\%$ & $60.31 \%$ & $39.31 \%$ & $22.89 \%$ & $15.14 \%$ \\
\hline
\end{tabular}

Table 3 shows the optimal placement and the optimal size of type-2 DG installed into the system.

Table 3. Optimal DG Type-2 Placement of the System

\begin{tabular}{ccccc}
\hline DG installed & DG Type 2 & DG Type 2 & DG Type 2 & DG Type 2 \\
\hline Location & 24 & 30 & 5 & 33 \\
QDG size, MW & 2.7 & 35.3 & 10.3 & 4.01 \\
Qloss, MW & 0.0491 & -1.72 & 0.1644 & 0.05015 \\
Qloss reduction, $\%$ & $39.69 \%$ & $52.65 \%$ & $47.84 \%$ & $40.59 \%$ \\
\hline
\end{tabular}

Table 4 shows the optimal location and the optimal size for type-3 DG at 36 bus distribution system in Myanmar.

Table 4. Optimal DG Type-3 Placement of the System

\begin{tabular}{ccccc}
\hline DG installed & DG Type 3 & DG Type 3 & DG Type 3 & DG Type 3 \\
\hline Location & 24 & 30 & 5 & 33 \\
PDG size, MW & 6.97 & 93.7 & 32.3 & 8.94 \\
Ploss, MW & 0.1949 & 0.1283 & 0.07048 & 0.1385 \\
Ploss reduction, $\%$ & $29.56 \%$ & $9.429 \%$ & $83.17 \%$ & $24.86 \%$ \\
\hline
\end{tabular}

Table 5 shows the optimal location (bus number) and size $\left(\mathrm{P}_{\mathrm{DG}}\right.$ size and $\mathrm{Q}_{\mathrm{DG}}$ size are real and reactive capacity of DG installed, respectively) for different types of DG installed into the system.

Table 5. Optimal DG Placement of the System for DG Placement

\begin{tabular}{|c|c|c|c|c|}
\hline DG installed & DG Type 1 & DG Type 2 & DG Type 3 & DG Type 4 \\
\hline Location & 24 & 30 & 5 & 33 \\
\hline PDG size, MW & 6.43 & & 32.3 & 5.71 \\
\hline Ploss, MW & 0.1098 & 4.004 & 0.07048 & 0.0964 \\
\hline Qloss, MVAr & 0.04911 & -1.72 & 0.01845 & 0.07817 \\
\hline
\end{tabular}

These tables also present the information of real (Ploss reduction) and reactive power loss reduction (Qloss reduction) in term of percentage, and total real (Ploss) and reactive power loss (Qloss) in term of MW and MVAR, respectively.

The results in these tables show the significant real and reactive power loss reduction after installation of DG in the system. In addition, optimal size and location of DG are also changed with different type of DG installed in the system.

DG type 1 can reduce the real and reactive power loss by $60.31 \% \& 74.39 \%$ compared to $52.65 \%$ $\& 66.5 \%, 83.17 \%$ \& $94.16 \%$, and $50.49 \%$ \& $34.39 \%$ for DG type 2 , DG type 3 , and DG type 4 , respectively.

\section{a. Optimum Bus Voltage Profile}

The Voltage at various buses should be maintained within the acceptable limits to meet out the power system demand. But the Bus voltage may reach the permissible limit when DG is not connected to the 
distribution system or the bus voltage may lack due to some disturbances. For this reason Distributed Generation should be placed and sized at the relevant bus location in radial Distribution system so that the bus voltage profile gets improved. The improvement of voltage profile of the system for different types of DG installed is shown in Figure 7.

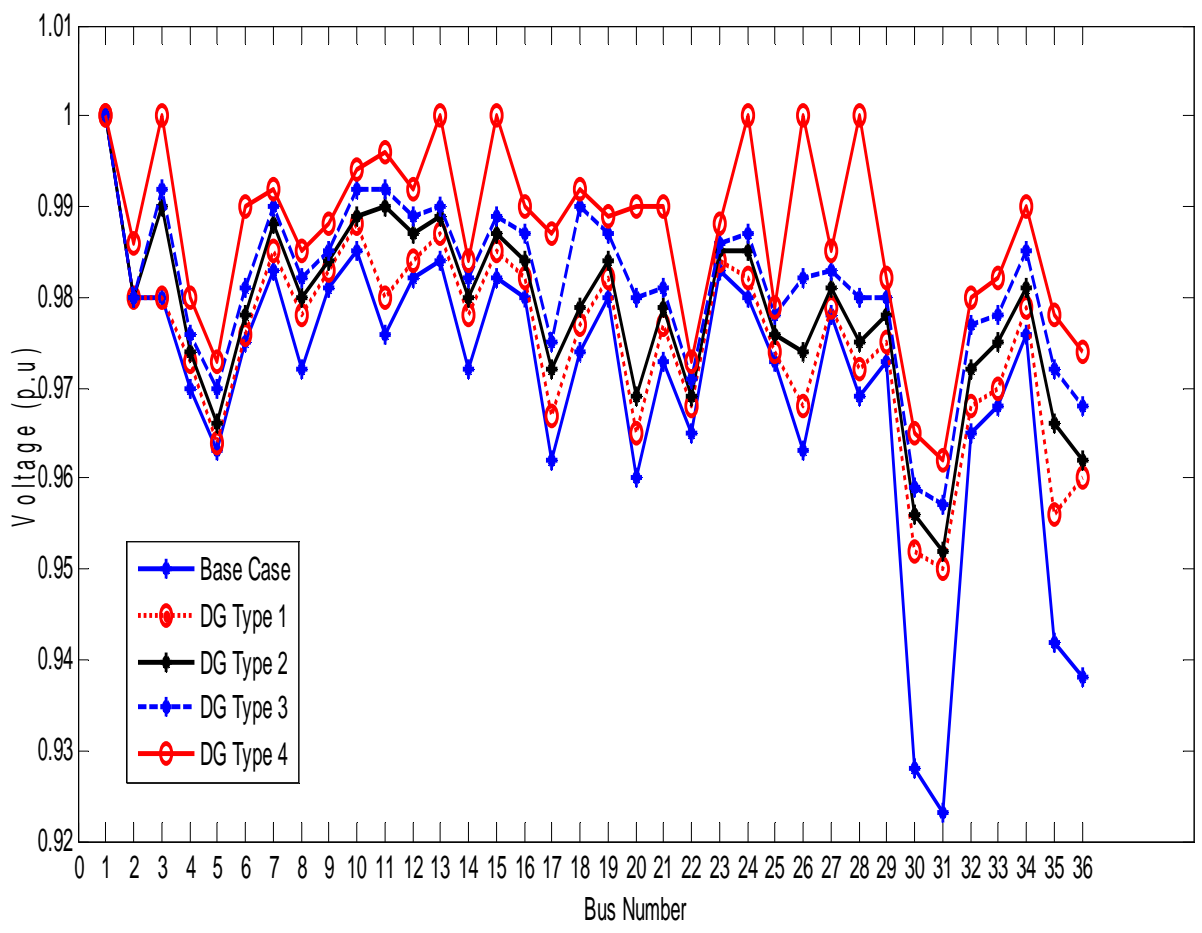

Figure 7. Variation of voltage profile for 36 bus distribution system

\section{CONCLUSION}

Different types of DG installed in the system have different impacts on reactive power loss reduction. Optimal size and location of DG are also changed with different type of DG installed in the system. Exact loss formula is used to determine optimal size and the location for type-1, type-2, type- 3 and type-4 DGs. The four types of DGs effectively reduced the real power loss, reactive power loss and voltage profile are also improved.

DG type 3 has the most effective way of reducing real and reactive power loss, following by DG type 1, DG type 2, and DG type 4, respectively. It is also interesting to note that DG type 3 has the highest loss reduction since it can generate both real and reactive power and DG type 4 has the lowest loss reduction since it consumes reactive power in the system.

The methodology of finding proper location and size of DG in order to minimize real and reactive power losses in radial distribution system is more effective in term of voltage improvement than that of finding proper location and size of DG in order to minimize real and reactive power losses. 
Appendix A

Line Parameters and Load Data of 36-bus Distribution System

\begin{tabular}{|c|c|c|c|c|c|c|}
\hline \multicolumn{4}{|c|}{ Line Parameters } & \multicolumn{3}{|c|}{ Load Data } \\
\hline $\begin{array}{c}\text { From Bus } \\
\text { No. }\end{array}$ & To Bus No. & R (p.u) & X (p.u) & Bus No. & P (p.u) & Q (p.u) \\
\hline 1 & 2 & 0.0002 & 0.0003 & 1. & 200 & 198 \\
\hline 2 & 4 & 0.0195 & 0.0365 & 3. & 1.19 & 1.142 \\
\hline 4 & 32 & 0.1332 & 0.1540 & 4. & 8 & 6.5 \\
\hline 4 & 33 & 0.1332 & 0.1540 & 5. & 6.17 & 5.37 \\
\hline 6 & 34 & 0.0444 & 0.0513 & 8. & 2.06 & 2.045 \\
\hline 6 & 35 & 0.3553 & 0.4109 & 9. & 2.04 & 2.03 \\
\hline 6 & 36 & 0.8883 & 1.0272 & 10. & 2.91 & 2.75 \\
\hline 2 & 7 & 0.0017 & 0.0031 & 11. & 2.71 & 2.15 \\
\hline 2 & 8 & 0.0014 & 0.0026 & 12. & 2.54 & 2.03 \\
\hline 2 & 13 & 0.0006 & 0.0010 & 17. & 2.84 & 2.613 \\
\hline 2 & 14 & 0.0005 & 0.0008 & 18. & 2.4 & 2.13 \\
\hline 2 & 15 & 0.0004 & 0.0008 & 19. & 2.45 & 2.338 \\
\hline 2 & 16 & 0.0119 & 0.0221 & 20. & 2.45 & 2.338 \\
\hline 2 & 17 & 0.0009 & 0.0016 & 21. & 2.54 & 2.15 \\
\hline 2 & 18 & 0.0009 & 0.0017 & 22. & 2.5 & 2.037 \\
\hline 2 & 19 & 0.0047 & 0.0088 & 23. & 2.39 & 2.225 \\
\hline 2 & 20 & 0.0020 & 0.0038 & 24. & 2.57 & 2.31 \\
\hline 2 & 21 & 0.0016 & 0.0031 & 25. & 4.2 & 3.15 \\
\hline 2 & 22 & 0.0017 & 0.0031 & 26. & 8.4 & 6.3 \\
\hline 2 & 23 & 0.0011 & 0.0020 & 27. & 2.2 & 2.15 \\
\hline 2 & 24 & 0.0011 & 0.0021 & 28. & 2.02 & 2.015 \\
\hline & & & & 36. & 2.53 & 2.373 \\
\hline
\end{tabular}

\section{ACKNOWLEDGEMENT}

The authors are deeply grateful to U Kyaw Win and Daw Kyi Htay for their supports and encouragement to attain her destination without any trouble and all the persons who share the trouble of the author on any situation in trying this paper.

\section{REFERENCES}

[1] Niknam T, Taheri SI, Aghaei J, Tabatabaei S, Nayeripour M. A modified honey bee mating optimization algorithm for multiobjective placement of renewable energy resources. Appl Energy 2011; 88(12): 4817-30.

[2] Taher N. A new HBMO algorithm for multiobjective daily Volt/Var control in distribution systems considering distributed generators. Appl Energy 2011; 88(3): 778-88.

[3] Martinez-Rojas M, Sumper A, Gomis-Bellmunt O, Sudrià-Andreu A. Reactive power dispatch in wind farms using particle swarm optimization technique and feasible solutions search. Appl Energy 2011; 88(12): 4678-86.

[4] Manfren M, Caputo P, Costa G. Paradigm shift in urban energy systems through distributed generation: Methods and models. Appl Energy 2011; 88(4): 1032-48.

[5] Bakos GC. Distributed power generation: a case study of small scale PV power plant in Greece. Appl Energy 2009; 86(9): 1757-66.

[6] W.El-Khattam, M.M.A.Salama, "Distributed Generation Technologies, definitions and benefits", Electric Power Systems Research, Vol. No.71, pp. 119-128, 2004.

[7] Thomas Ackermann, Goran Andersson, Lennart Soder, "Distributed Generation: a definition", Electric Power Systems Research, Vol. No. 57, pp.195-204, 2001.

[8] Carmen L.T. Borges, Djalma M. Falcao, "Optimal Distributed Generation allocation for reliability, losses and voltage improvement", Electrical power and Energy systems, Vol. No. 28, pp. 413-420, 2006. 


\section{BIOGRAPHIES OF AUTHORS}

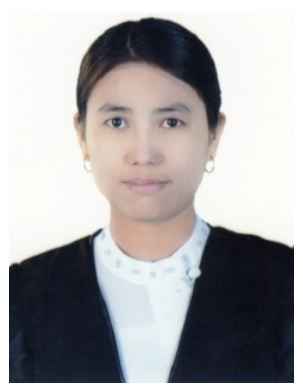

Ms. Su Hlaing Win. She was born on $24^{\text {th }}$ August 1983. I am thirty two years old. She studied $\mathrm{BE}$ and $\mathrm{ME}$ at Technological University (Monywa). And she is working as an assistant lecturer at Technological University (Kyaukse). Now, she is Ph.D candidate at Electrical Power Engineering Department at Mandalay Tecnological University. She got ICSE paper that held in Inyar lake hotel in Myanmar and International paper of ICTAEECE Conference that held in Bangkok during this year. Her email is suhlaingwin24@gmail.com.

Pyone Lai Swe, Associate Professor Department of Electrical Power Engineering, Mandalay Technological University, Mandalay, Myanmar. email: pyonelai@gmail.com 